\title{
Metallurgical Analysis of Steel Plate for Deep Drawing Application
}

\author{
Victor Yuardi Risonarta ${ }^{1, a}$, Huffal Azhar Fadly ${ }^{2}$, Hafidh Frian Perdana ${ }^{2}$ \\ ${ }^{1}$ Department of Industrial Engineering, Catholic University of Darma Cendika, Surabaya, Indonesia \\ ${ }^{2}$ Department of Materials and Metallurgical Engineering, Sepuluh Nopember Institute of Technology, Surabaya, Indonesia \\ ${ }^{a}$ victor. yuardi@ukdc.ac.id
}

\begin{abstract}
Deep drawing is one of metal forming manufacturing processes which can be used to produce many products, e.g. kitchen ware, automotive parts, etc. Although this particular manufacturing company has applied the Japanese standard JIS G 3141 as guidance to select a steel plate for deep drawing application, the deep drawing process at this company is still failed. Therefore, this manuscript discusses more deeply the metallurgical analysis of selected steel plates to produce a deep-drawn product with 0.5 thickness. Analysis presented in this manuscript comprises the influence of chemical composition of a steel plate on its mechanical property, i.e., tensile strength, elongation, and hardness. As a result, a correlation between chemical composition and expected mechanical property to manufacture a drink cup is outlined. Moreover, recommended chemical composition of a steel plate is also presented.
\end{abstract}

Keywords: Deep Drawing, Materials Selection, Chemical Composition, Mechanical Property.

\section{Introduction}

Nowadays, the selection of kitchen ware product always considers its aesthetic and functionality. One of the kitchen ware often used in daily life is a drink cup. In this manuscript, the selection of steel plate materials for deep drawing process is outlined. Deep drawing process discussed in this work is to manufacture a drink cup whose diamater $\left(R_{p}\right)$ is $12 \mathrm{~cm}$ and height is $14 \mathrm{~cm}$. In the deep drawing process, force is applied both to hold a steel plate (blank) as well as a pressure fore from the punch (Figure 1). In the end, the punch force will change the steel blank into a drink cup due to stretching of steel blank according to dimension and shape of the die.

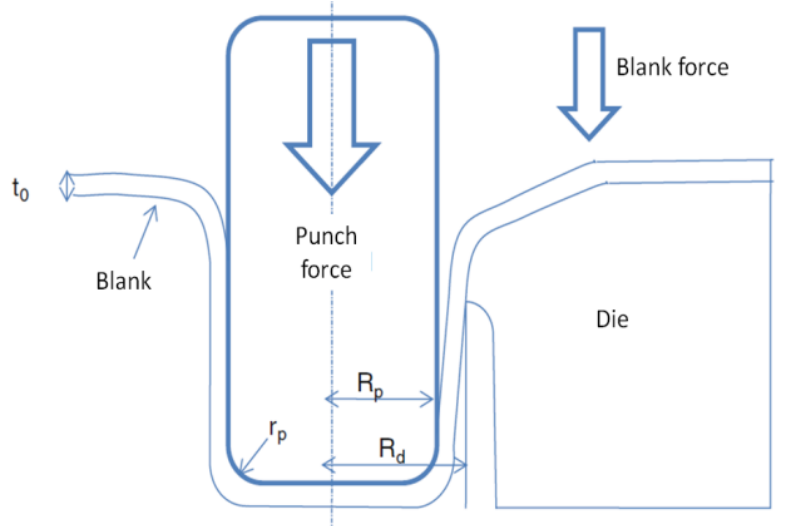

Note:

$\mathrm{t}_{0}$ : Initial plate thickness

$\mathrm{R}_{\mathrm{p}}:$ product radius

$\mathrm{R}_{\mathrm{d}}$ : die radius

Figure 1. Schematic of deep drawing process [1]

The drink cup is manufactured through following steps:

1. Blanking

Blanking is the first step in the deep drawing process.

During the blanking process, a steel plate is cut into a round steel plate. For this product, the initial steel plate as the product of blanking has a diameter of $22 \mathrm{~cm}$ and a thickness of $0.5 \mathrm{~mm}$.

2. Deep drawing

During the deep drawing, the steel blank is formed by using a punch and die. Depending on the ratio between the steel blank and the product diameters, the deep drawing process can be performed in one or more steps. If the ratio between the steel blank diameter and the product diameter is higher than 2 , the deep drawing process should then be worked out in more than one step to prevent crack.

\section{Forming}

During piercing, the top part of the semi-finished is punched to form a circular flange.

\section{Trimming}

In the trimming process, excess material is truncated from the deep drawn product.

In order to produce good and nice shape of product as well as to prevent defect during the deep drawing process, the selected steel blank should fulfill several mechanical and metallurgical properties. Required characteristics of the steel blank and process parameters are as follows [2]:

- Hardness of the blank and hardness of die

- Chemical composition of the steel blank

- Yield point and ultimate tensile strength (UTS) of the steel blank

- Grain size of the steel blank

- Uniformity on mechanical and metallurgical properies

- Pressure force and design of punch

- Holding force and design of die

- Strain rate during the deep drawing process

- Initial blank dimension and final product dimension

- Lubricants used in the gap between punch, the steel blank, and die 
If the above mechanical and metallurgical properties as well as process parameters are well selected, the product of the deep drawing process will not experience any defect, e.g. wrinkle, tear or orange peel (Figures 2 and 3).
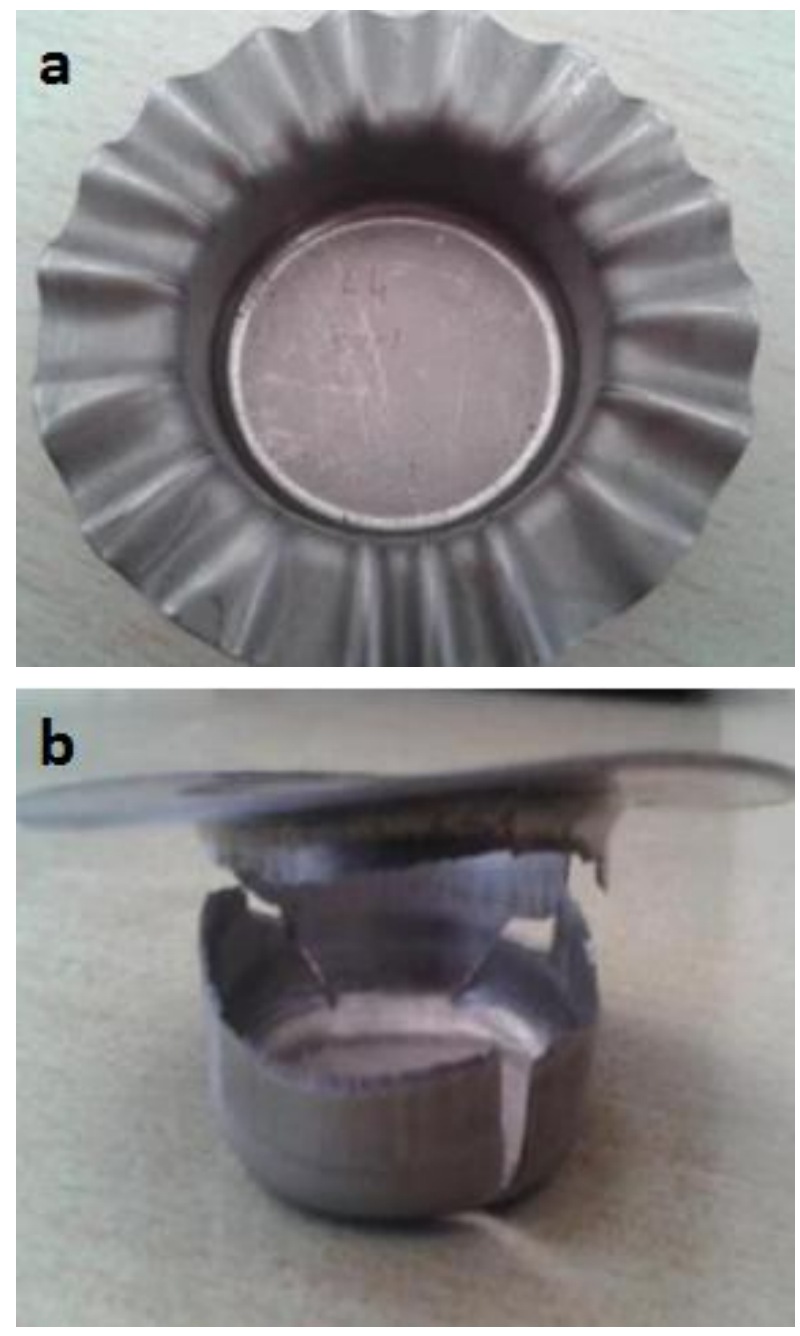

Figure 2: Defect of deep drawing product: wrinkle (a) and tear (b)

\section{Mechanical Properties}

The steel blank should have relatively a low yield point. The punch force should be higher than the yield point of the steel plate, so that the product will plastically deform without any springback defect. If the steel blank has a high yield point, higher punch force is required to form the product. This will lead to high load and energy consumption of the deep drawing machine. On the other hand, the steel blank should have a high ultimate tensile strength (UTS) and elongation to prevent tear and crack defect. Therefore this work investigates the required minimum value of elongation and UTS to prevent crack and tear defect. Hardness of the steel blank is also investigated in this work. Higher hardness leads to difficult deep drawing process since it leads to higher punch force.


Figure 3: Surface of deep drawing product. Without orange peel defect (a) and with orange peel defect (b)

\section{Methodology}

Initial steel blank materials are received from 3 different suppliers. Every steel blank has initial thickness of $0.5 \mathrm{~mm}$. The blanking process is applied to prepare tensile test and hardness test speciments. For every blank material, there are 5 tensile test speciments, so in total there are 15 tensile test speciments. For every steel blank, there are 10 sampling points so there are 30 sampling points for hardness test.

Hardness test was conducted following the Brinnel method according to the ASTM Standard E10. Hardness test was performed by using Wolpert UH930 in the Metallurgical Laboratory at the Department of Materials and Metallurgical Engineering, Sepuluh Nopember Institute of Technology, Surabaya. For every blank material, 10 points were tested with a load of $100 \mathrm{kgf}$ for 10 second by using a hardened steel ball indenter.

Figure 4 shows the dimension of a tensile test speciment which was prepared according to the JIS Standard Z 2201. The tensile test was performed by using the Universal Testing Machine (Instron UTM) in the Metallurgical Laboratory at the Department of Materials and Metallurgical Engineering, Sepuluh Nopember Institute of Technology, Surabaya. The method for tensile test was following the JIS Standard Z 2241.

The chemical composition of blank materials was characterized by using FEI INSPECT S50 with voltage of $10 \mathrm{MV}$ in the Laboratory of Materials Characterization in the Metallurgical Laboratory at the Department of Materials 
and Metallurgical Engineering, Sepuluh Nopember Institute of Technology, Surabaya. The characterization of chemical composition follows the ASTM standard A571 containing the method for chemical analysis of steel, stainless steel and other steel alloy [4].

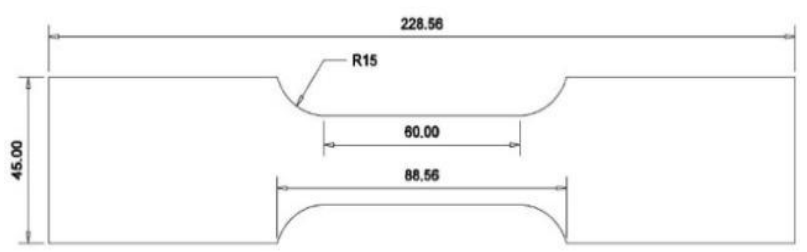

Figure 4. Dimension of tensile test in this work (dimension in $\mathrm{mm}$ - following the JIS Standard Z 2201) [3]

\section{Result and Discussion}

Characterization of chemical composition shows that Ferrous (Fe) concentration in the steel blank is almost similar, i.e., between 99.4 and $99.5 \%$ wt (Table 1). The H1 steel blank shows significant different concentration of Carbon (C) and Titanium (Ti). Carbon concentration of the H1 steel blank is $0.006 \%$ wt and this is lower than that of the A1 and P1 steel blanks which have carbon concentration of $0.027 \%$ wt and $0.029 \% w t$, respectively. Meanwhile, Titanium concentration of the $\mathrm{H} 1$ steel blank is $0.0416 \%$ wt which is significantly higher than that of the A1 and P1 steel blanks. Manganese $(\mathrm{Mn})$ concentration does not differ significantly for these three steel blanks, i.e., between 0.14 and $0.22 \%$ wt. Manganese will be diluted in ferrite so it will increase hardness and strength of the ferrite. Additionally, Manganese acts also as a carbide stabilizer. The composition of these three steel blanks is already in agreement with the chemical composition for a deep drawing steel blank recommended by the JIS Standard G 3141 .

Result of the hardness test shows that the hardnesses of all three steel blanks do not differ significantly (Table 2). The hardness value is in the range of 28.2 and $34.1 \mathrm{HRB}$. Result of the tensile test shows that all steel blanks are already in agreement with the JIS Standard G 3141, i.e., the elongation is higher than $36 \%$, the yield strength is lower than $240 \mathrm{MPa}$ and UTS is higher than $270 \mathrm{MPa}$. The H1 steel blank has the highest elongation, i.e., $44.5 \%$. Meanwhile, the P1 steel blank has the lowest yield strength at $173.5 \mathrm{MPa}$ and the highest UTS value at $318.6 \mathrm{MPa}$.

Although the results of the tensile test are in agreement with the JIS Standard G 3141, only the deep drawing of H1 steel blank results in no defect. After being deep drawn, the A1 steel blank shows tear defect and the P1 steel blank shows orange peel defect. Although orange peel defect does not influence product strength, orange peel defect for this product is not acceptable from the aesthetic point of view. Therefore, the JIS Standard G 3141 should be adapted for each deep drawing application.

\subsection{Analysis of Microstructure and Chemical Compo- sition}

Figure 5 shows the microstructure of three steel plates. The pictures were produced in the Metallurgical.
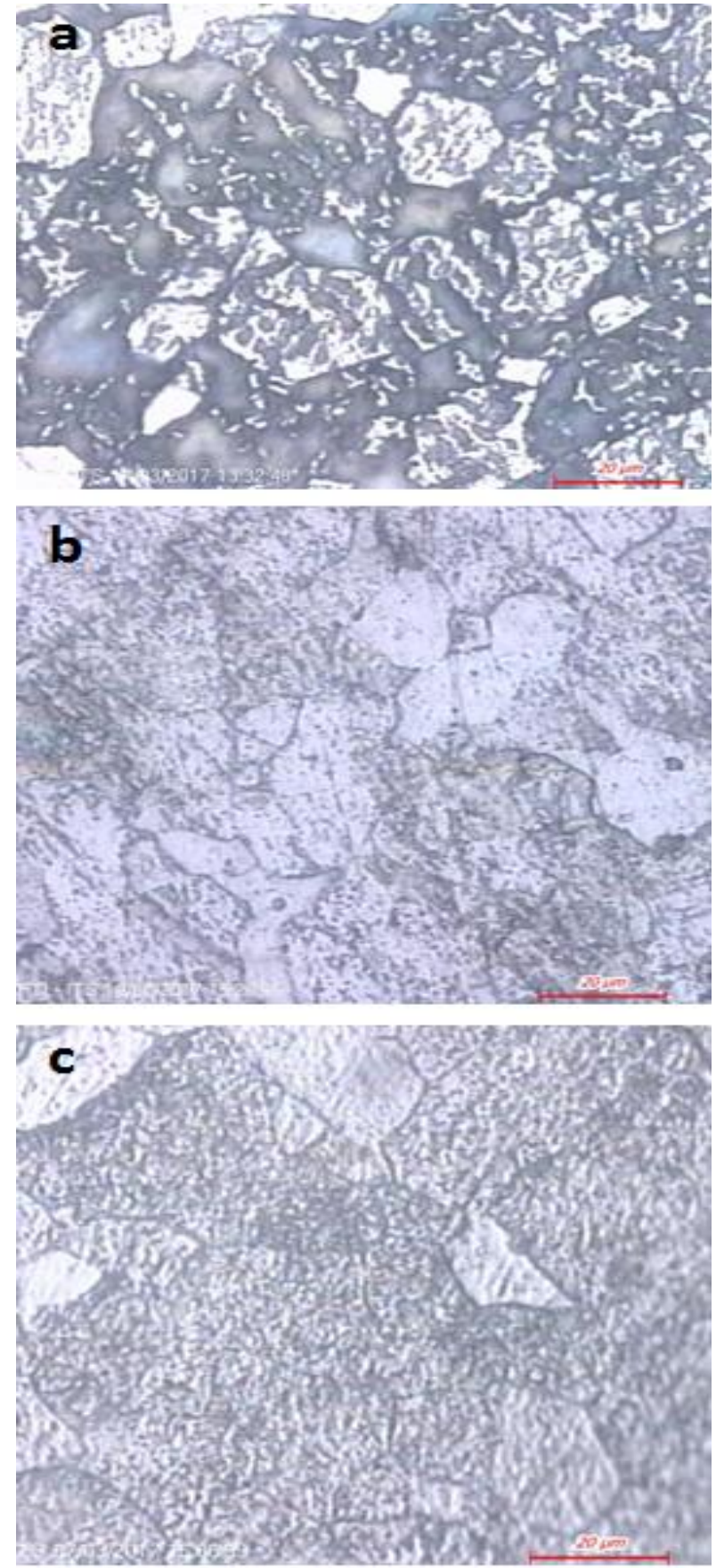

Figure 5: Microstructure of steel plate with 50x magnification: $\mathrm{H} 1$ plate (a), A1 plate (b) and P1 plate (c)

Laboratory at the Department of Materials and Metallurgical Engineering, Sepuluh Nopember Institute of Technology, Surabaya. The H1 steel blank has carbon concen-

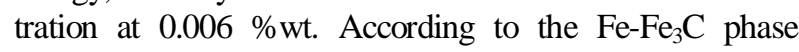
diagram, the $\mathrm{H} 1$ steel blank has ferrite $\left(\mathrm{Fe}_{\alpha}\right)$ phase [6]. Ferrite is ductile and soft, so it has good ability of forming, deep drawing, as well as machining (blanking and trimming). However, ferrite has low UTS value. Titanium is therefore added as much as $0.0416 \%$ in the $\mathrm{H} 1$ steel blank, which is significantly higher than that of the A1 and P1 steel blanks. This is done to increase the strength of $\mathrm{H} 1$ steel blank. Added Titanium forms carbide or nitride in very fine size which is dispersed in steel [6]. Grain size of the H1 
Table 1. Result of chemical composition characterization for three steel blanks and comparison with the JIS Standard G 3141

\begin{tabular}{ccccccc}
\hline \multirow{2}{*}{ Steel blank } & \multirow{2}{*}{ Number of samples } & \multicolumn{5}{c}{ Chemical composition [\% wt] } \\
\cline { 2 - 7 } & 5 & $\mathbf{C}$ & $\mathbf{M n}$ & $\mathbf{S i}$ & $\mathbf{T i}$ & $\mathbf{F e}$ \\
\hline H1 & 5 & 0.006 & 0.14 & 0.151 & 0.0416 & 99.5 \\
A1 & 5 & 0.027 & 0.21 & 0.222 & 0.0002 & 99.4 \\
P1 & 0.029 & 0.22 & 0.202 & 0.0002 & 99.4 \\
\hline JIS Standard G 3141 [5] & Max. 0.12 & Max. 0.5 & - & - & - \\
\hline
\end{tabular}

Table 2. Average value of hardness and tensile test result

\begin{tabular}{cccccc}
\hline Steel blank & Number of sample point & Hardness [HRB] & Yield strength [\%] & Yield point [MPa] & UTS [MPa] \\
\hline H1 & 10 & 28.2 & 44.5 & 199.1 & 296.5 \\
A1 & 10 & 33.7 & 40.2 & 196.4 & 293.4 \\
P1 & 10 & 34.1 & 42.1 & 173.5 & 318.6 \\
\hline JIS Standard G 3141 [5] & - & Min. 36 & Max. 240 & Min. 270 \\
\hline
\end{tabular}

plate is relatively smaller than that of the A1 plate. This fine size prevents grain growth so it will produce small grain size. If a steel blank has small grain size, the steel blank becomes stronger. Additionaly, small grain size prevents the orange peel defect. The H1 steel blank has elongation between 44 and $45 \%$ which is higher than that of the A1 and P1 steel blanks. Higher elongation value of the H1 steel blank is due to its ferrite content. Due to these properties, the H1 steel blank can be deep drawn without any defect.

Meanwhile, the A1 and P1 steel blanks have carbon concentration of 0.027 and $0.029 \%$ wt. These carbon concentrations are already higher than the solvus limit, i.e., $0.008 \%$ wt at room temperature [6]. This non-diluted carbon forms intermetallic bonding phase $\mathrm{Fe}_{3} \mathrm{C}$ (Cementite) which is found as a perlite. Cementite, which is commonly known as iron carbide, is an intermetallic compound. Its characteristic is hard and brittle. Higher presence of perlite increases strength and hardness but decreases ductility. Thus, the deep drawing ability decreases as well. For all steel blanks, values of elongation, yield strength, UTS resulting from the tensile test are already in agreement with the JIS Standard G 3141. However, A1 shows tear defect and P1 shows orange peel defect after being deep drawn. Orange peel defect is caused by the big grain size.

The most dominant alloy element for these three stell blanks is Manganese (Mn). Manganese will be diluted in ferrite which increases strength and hardness of the ferrite [6]. Mn also stabilizes carbide. Due to its high carbon concentration, Mangenese is added in higher oncentration in the A1 and P1 steel blanks. Manganese concentration is higher in the A1 and P1 steel blanks to stabilize the carbide. The A1 and P1 steel blanks form more carbide since their Carbon concentration at room temperature is more than $0.008 \%$ wt.

\section{Conclusion}

Selection of steel blank for this deep drawing process follows the JIS Standard G 3141. All three steel blanks are already in agreemement with the JIS Standard G 3141. However, only one steel blank, i.e., the H1 steel blank, is suitable for this particular deep drawing process. Carbon concentration of the H1 steel blank is low to avoid iron carbide formation in the steel. Therefore, Titanium is added in the H1 steel blank to increase its UTS value without significantly decreasing its elongation and significantly increasing its yield strength. Additionally, Titanium addition can suppress grain growth which is responsible for orange peel defect in the deep drawn product.

\section{References}

1. Hingole, R.S., Advances in Metal Forming, Springer Series in Materials Science, 206, Springer, BerlinHeidelberg (Germany), 2015, p. 3.

2. Altan, T. and Tekkaya, A.E., Sheet Metal Forming: Fundamentals, ASM International, 2012.

3. Japanese Standards Association, JIS Z 2241: Method of Tensile Test for Metallic Materials, Japanese Standards Association, 1998.

4. Dulski, T.R., A Manual for the Chemical Analysis of Metals, ASTM International, 1997.

5. Japanese Standards Association, JIS G 3141: ColdReduced Carbon Steel Sheet and Strip, Japanese Standards Association, 2009.

6. Callister, W.D. Jr. and Rethwisch, D.G., Fundamentals of Materials Science and Engineering: An Integrated Approach, $4^{\text {th }}$ ed., John Wiley \& Sons, New Jersey, 2012. 